\title{
An Academic Development Agenda for Postgraduate Research Students
}

\author{
Newman Wadesango (PhD) \\ Teaching and Learning Centre, University of Fort Hare, South Africa, \\ Email: nwadesango@ufh.ac.za
}

Cosmas Maphosa (PhD)

Faculty of Education, University of Fort Hare, South Africa

George Moyo (PhD)

Faculty of Education, University of Fort Hare, South Africa

\section{Doi:10.5901/mjss.2014.v5n11p49}

\begin{abstract}
There is concern in the South African higher education system of the low production of post graduate research graduates. A knowledge economy is driven by skilled and research trained personnel yet the low graduation rates at Masters and PhD levels is a cause for concern. In this paper we interrogate the relationship between a knowledge economy and the quantity and quality of post graduates. The purpose of post graduate research degrees is explored and factors affecting dissertation and theses completion by postgraduate students are discussed. The concept academic development is discussed and ways of academically developing post graduate research students are explored.
\end{abstract}

Keywords: Academic development, post graduate, research, students, higher education

\section{Introduction}

The development of any country is ordinarily driven by a knowledge economy. In defining a knowledge economy, Powell and Snellman (2004: 201) say:

We define the knowledge economy as production and services based on knowledge- intensive activities that contribute to an accelerated pace of technical and scientific advance, as well as rapid obsolescence.

The above alludes to the necessary attributes higher education graduates should have in order to drive the knowledge economy. Graduates should be able to actively participate in production and services using acquired knowledge and skills. A knowledge economy is driven by intellectual capabilities of individuals and not on physical inputs and natural resources (Powell and Snellman, 2004).

Houghton and Sheehan (2000) advance the view that economic activities based on knowledge stimulate economic growth and make a country competitive on the global market. Blankley and Booyens (2010) note the three major ingredients in the making of a knowledge based economy which are new technology investment, high-technology industries and highly skilled labour. Universities have to respond in providing highly skilled graduates who are the key drivers of a knowledge economy. Blankley and Booyens (2010: 376) state that:

Highly skilled human resources are the most critical component when it comes to building a country's capacity for a knowledge-based economy.

The importance of highly skilled personnel in a knowledge-based economy cannot be overemphasised hence the need to ensure that institutions of higher learning produce graduates that fit into the knowledge-based economy in terms of possessing the appropriate graduate attributes.

Griesel and Parker (2009) note that there graduate attributes that are expected from graduates by employers. It is the possession of such attributes that makes the graduates employable. Griesel and Parker (2009) further advance the view that graduate attributes include knowledge and intellectual ability as well as workplace skills and applied knowledge. 
This shows that graduates should have sufficient knowledge and skills to perform and they should demonstrate ability to applied competence to workplace tasks.

\section{The Relationship between Knowledge Economy and Post Graduate Studies}

Our society has changed dramatically over the past few years. Growing pluralisation (versatility and diversification of our communities) and individualisation (emphasis on emancipation and autonomy) are some of the main trends of our society (Zhao, 2001). It is clear that knowledge-based industries are increasingly becoming a key part of our industrial landscape. Zhao further asserts that the western economy has evolved into a knowledge economy in which knowledge has become the main competition tool for business and a vital economic resource. Furthermore, the process of knowledge management through knowledge construction, dissemination, use and embodiment starts to gain momentum in knowledge-based industries and our society. This therefore implies that the changing environment has profound implications for research education/training in universities where knowledge business dominates.

Post graduate research supervision is a process of fostering and enhancing learning, research and communication at the highest level (Laske \& Zuber-Skerritt, 1996; Zhao 2001). Connell (1985) maintained that research supervision is the most advanced level of teaching in the educational system. The supervisory process is crucial to the success of post graduate students and certainly complex, subtle, pivotal and responsible. Although there have been calls to conceptualise research supervision as a teaching/learning process, there is still a tendency to equate it with research training and with the research responsibilities of the academic role (Johnston, 1999, Zhao, 2001). In the view of supervisors, their supervision should be able to contribute to the advancement of scientific knowledge through creating effective learning/research situations and entail opportunities for supervisors to conduct research projects with students which may enhance their own learning, research and reputation (Zhao, 2001). From the perspective of universities and society, post graduate supervision increases the links between universities and industries/communities and contributes to the production of high- level scientists (Laske and Zuber-Skerritt, 1996, Zhao, 2001)

It is imperative that post graduate supervisors adopt the knowledge management model in order to link knowledge economy and post graduate studies. Zhao (2001) explains that the knowledge management model explores knowledge management from the perspective of operational process, that is, the basic input-output transformation process. At the input end, we have a combination of knowledge of customer's needs and expectations, knowledge of raw materials and resources to be used, knowledge of products and services to be delivered as well as data information or knowledge. The process clearly indicates that knowledge management takes information, knowledge and people as its basic inputs, and applied knowledge and intellectual capital as its desired outputs (Armistead, 1999; Zhao, 2001). Knowledge management in different organisations may serve different purposes. Universities have a significant level of knowledge management activities associated with the creation and maintenance of knowledge repositories, improving knowledge access, enhancing knowledge environment and valuing knowledge (Rowley, 2000; Zhao, 2001). The supervision of research students is therefore undoubtedly an integral part of the knowledge management activities in universities. In other words, the effectiveness of post graduate research supervision process to achieve quality improvement and increased productivity will be enhanced if knowledge management concepts are effectively integrated into the process.

This study reports that there have been persistent concerns about the quality and breadth of research training especially in South African Universities. These persistent concerns have been voiced by users/consumers of research training (Singh and Knight, 2005), namely graduate students and industry employers. These groups report that research training is often 'narrow and limiting in its specialisation; poorly supervised and out of line with the needs and expectations of employers' (Kemp, 1999: 10). The 1998 Research Training paper adds detail to this issue, noting under the header 'Quality of Supervision' the following skills that are considered 'to be in demand by research and development managers': fluency of ideas, information ordering, logical reasoning, oral communication, originality, persistence, social sensitivity, persuasion, problem sensitivity, resistance to premature judgement and written communication (DETYA, 1998; Singh and Knight, 2005). The higher education therefore needs resilient absorptive capacity for accommodating unforeseen changes in demand, organisational flexibility, resource and staffing flexibility, a range of effective pathways for learning including modes of learning, delivery methods, assessment, and availability of learning resources (Singh and Knight, 2005). They refer here (Singh and Knight, 2005) not only to the by-now well-known process of macromanagement (nicely described as "steering at a distance" by Kickert, 1991) in which autonomy to deliver broadly specified programs and services is balanced by tighter accountability measures (Knight \& Lingard, 1997), but also to increasing pressure to change the traditional content and processes of higher education to meet the demands of the socalled post-Industrial (Bell, 1973), post-modern (Lyotard, 1985), informational (Castells, 2000), and globalised economy (Harvey, 1989). 
They note, for example, the shift in practice and values from truth to knowledge to power, from pure to applied research, from science to technology, the commodification and commercialization of knowledge, the marketization of education as a product, with clients, consumers, and value-added products (Singh and Knight, 2005). Thus, Lyotard (1985) concludes that the critical issues for higher education have become 'What use is it', 'Is it saleable?' and 'Is it efficient?' In other words (Knight \& Lingard, 1997) describe a post graduate research training program that aim to be 'learner-centred', 'high quality', 'equitable', 'responsive', 'diverse', 'innovative', 'flexible', 'cost-effective', 'publicly accountable' and 'socially responsible' (DEST, 2002: 2-3). Furthermore, a proper post graduate research training should also attempt to construct a pedagogic context in which students acquire the information/knowledge resources considered important to prospective employers, namely, information ordering, logical reasoning, persistence, social sensitivity, problem sensitivity, and oral and written communication skills (DETYA, 1998: 4). It is also believed that the quality of post graduate supervision is the most significant variable influencing signage between knowledge economy and post graduate studies. Academics (Deem \& Brehony, 2000; Green \& Lee, 1999) propose that postgraduate research supervision is one of the most complex and advanced forms of teaching. From this perspective, supervisors need to be trained/educated in the pedagogical content knowledge of post graduate research supervision.

A number of researchers have discussed the implications of the exponential growth in discipline specific research knowledge to post graduate research training (Singh and Knight, 2005). Specifically, they argue that universities are no longer the sole and/or key sites or institutions for the generation of new knowledge (Clark cited in Cowen, 1996; Johnston, 1998; Singh and Knight, 2005). In support, Burger (2013) explains that for South African companies to compete with international companies, it is imperative that they have access to new ideas and that the country institutionalises the generation of new ideas. Universities can therefore function as research and innovation cores for networks of technology institutions, companies and new enterprises that will develop and commercialise information and technology (Burger, 2013). Qhena (2013) concurs with Burger in that South Africa is a small and open economy, perforce competing with international companies and prices. To establish, grow and sustain companies, new ideas must continuously be developed by universities.

If we are not researching, we are not creating knowledge. If we do not have knowledge, then we cannot innovate and cannot sell knowledge to drive the economy. South Africa has neglected the relationships between its universities and industry," Du Pré (2013) says. Furthermore she asserts that South Africa needs to strengthen its capacity for hightechnology training. A knowledge economy requires postgraduate research output because the knowledge can then be sold and used in innovation by enterprises. Similarly, the universities must have adequate research infrastructure to provide knowledge and research for innovation and commercialisation by enterprises. Du Pré points to knowledge clusters worldwide, each of which developed around the nucleus of a university. The most renowned technology cluster, Silicon Valley, developed because of its close proximity to the skilled people, knowledge and innovation stemming from the universities of Stanford and California, in the US. "The universities at the heart of knowledge clusters create not only knowledge, but also spin-off companies, as a result of research, which attracts industry firms. These firms use the knowledge and then form the heart of a knowledge region, where technical universities and technology institutions support the development of high-technology industrial companies. South Africa must increase its post- graduate and research output to generate useful knowledge for industry. Commercial incentives may be effective to increase interest in and the generation of research. Industries and sectors must collaborate with universities (Du Pré, 2013). These collaborations should then be incubated, grown and commercialised in partnership. This collaborative approach between industry and academia is necessary for South Africa to generate knowledge, drive innovation, create high-technology clusters and business incubators by providing the high- level research that technology companies need (Du Pré, 2013).

Higher education and research have come to the forefront of international debates about economic growth (Tzanakou, 2012). There has been a growing consensus among policy-makers that post-industrial society requires more highly-educated people with technical and professional skills in a knowledge-based economy. Doctoral education has become of paramount significance in a world where knowledge becomes the new 'fuel', the ultimate economic renewable to economic growth leading to a knowledge-based economy (Brinkley, 2006; Leadbeater, 1999; Tzanakou, 2012). While there is still no consensus on the relationship between human capital and economic growth, post graduate holders who have accumulated substantial human capital through education have been identified as 'one of the key actors behind the creation of knowledge-based economic growth' (Auriol et al 2010. Tzanakou, 2012).

Sudman and Hawkey (2000) argue that students take the programs that are offered by institutions which are not responsive to demand, and the labour market in turn, is forced to absorb whatever is provided by an unresponsive public post-secondary system. This reasoning (Sudman and Hawkey, 2000) suggests that even though there is good evidence that non-technical graduates are successful, the important growth sectors of the economy - the knowledge economy does not need these graduates, that the "knowledge economy" is starved for high tech graduates, and a shift in 
educational output is required to stoke the growth of the new, high growth, knowledge economy. It is therefore imperative that post graduate studies be aligned with the needs of the economy.

The paper written by Sudman and Hawkey (2000) provides some evidence and conclusions for the analysis of the fundamental question: What mix of post graduate studies outputs (i.e., degrees, credentials) should the education system produce in response to the emergence of the knowledge economy?

The analysis proceeds in several stages:

1. Identify an operational definition for that sector of economy which is the "knowledge economy";

2. Provide evidence that the definition selects the sectors of the economy which indeed are desirable. It is clear that the labour force is becoming increasingly better educated, and that university graduates are easily absorbed into the labour market, but to suggest that this is evidence for the kind of workers required by the knowledge economy is circular.

3. Develop the "Educational Input-Output Matrix" (EIOM) to show the flows from post-secondary education into the various sectors of the labour market.

4. Develop and test hypotheses about the structure of the EIOM which suggest excess supply or demand (Sudman and Hawkey, 2000).

\title{
3. The Purpose of Post Graduate Research Degrees
}

The Department for Business, Innovation and Skills (DBIS) (2009) states that post graduate education is a critical strategic issue important for the production of postgraduates with higher level skills aligned to the requirements of industry. Kearney (2008) advances the view that post graduate education is important as a source of human capital and in promoting knowledge economy. Kearney (2008: 4) argues that:

\begin{abstract}
Post-graduate education constitutes a particular investment - whether personal or national - in human capital. Its overall objective is to educate highly skilled citizens and professionals able to address the specific issues of their national contexts as part of a wider globalised society.
\end{abstract}

It is clear from the above view that post graduate education should empower students with high level skills in order to participate fully in the economy of the country. Hazelkorn (2005) notes the importance of higher education as a key economic driver. The same view is shared by Murray (2002:31) regarding the importance of PhD graduates to the economy:

... knowledge based economy today puts far greater demands upon Doctoral graduates. There will always be a need for the subject specialist ...

Holders of postgraduate qualifications are important in driving the knowledge economy. Regarding professional doctorates, Phillip and Pugh (2005:197) state that:

Successful candidates (of the professional doctorate) will be skilled and experienced professionals who have not only practiced but pondered on and analysed the use of their academic and practical knowledge.

It is clear, in this view, that postgraduate programmes such as professional doctoral degrees assist very much in offering higher skills to professionals to enhance practice.

Badat (2010) notes that in doctoral graduates per million of population in 2003 South Africa lagged behind other countries. South Africa had 23 Doctoral graduates per million of population compared to Brazil with 43 per million, South Korea with 157 per million, Australia with 200 per million and Portugal -569 per million. As already alluded to, the number of $\mathrm{PhD}$ graduates in a country is important to drive the knowledge economy.

\section{Factors Affecting Masters and Phd Degrees Completion}

Department of Education, Education Statistics at a Glance (2003-2005) raises the challenge of non-completion of PhD programmes by students in South African universities. The same source records that in 2003 out of a total of $8380 \mathrm{PhD}$ candidates only 1032 completed in minimum time and 7348 did not complete. In 2005, out of a total 9434 candidates only 1187 graduated in minimum time and 8345 did not complete. Department of Education, Education Statistics at a Glance (2003-2005) notes that the average PhD graduation in South Africa is $12 \%$ and the non-completion rate is $88 \%$. This is a 
serious cause for concern, alluding to the need for viable support for postgraduate students.

There are a number of factors that affect the completion of postgraduate degrees by research. Such factors can be social, psychological or academic in nature. Green (1997) observes procrastination as one factor that hinders students' completion of dissertations. Procrastination is the 'the tendency to put off doing something until a future date unnecessarily' (Green, 1997: 58). This problem affects a lot of students. Students may not always do their work on time, waiting to do it at a later stage. This will result in students failing to get adequate time to work on their dissertations and theses and complete them within minimum time expected.

Perfectionism is also another factor that hinders students to complete their dissertations and theses on time. In perfectionism, students will take unnecessarily long time trying to work on chapter drafts in order to produce perfect drafts. The process involves a lot of trial attempts and a lot of time is wasted. The need to be perfect could be attributed to the desire high expectations of supervisors and peers. Inasmuch as there is need to ensure quality in one's presentation, wasting unnecessary time in order to achieve this may not be the best way to perfection.

Dietz, Jansen and Wadee (2006) identify common problems encountered by postgraduate research students as inadequate research background; lack of training in methodological and writing skills due to inadequate undergraduate training. Morton (2007) observes that training provided in research methods courses may not be sufficient to undertake rigors of doctoral and masters research. Hindrances to thesis completion include lack of understanding of the thesis writing process and difficulties in data collection (Ho, Wong \& Wong, 2010). Hollingsworth and Fassinger (2002) carried out a study and found that research training, through mentoring, prior to doctoral studies engagement enhanced research understanding and research practice.

Kamler and Thompson (2009) note that changes in technology could be a serious challenge in students' completion of dissertations and theses. Students hail from different socio-economic background and may grapple with engaging in internet searches from appropriate materials. Students may also struggle to present their work technologically using PowerPoint presentations. Effective utilisation of technology in postgraduate studies assists students in conducting literature review, gathering data and presenting findings.

\section{Ways to Academically Develop Post Graduate Students}

It is of paramount importance for universities to provide academic support that provides a personal and practical approach to academic study and opportunities for postgraduate students to develop their learning strategies. Post graduate students need certain support and guidance from their respective universities so as to become relevant to the needs of the economy. In support, Abidin (2011) explains that the learning that takes place during postgraduate studies is a maturing process. It must be enhanced with timely and appropriate support. Support and guidance should be provided to postgraduate students without sacrificing the coherence and generic input needed in any academic program. They further point out that there is no doubt that inaccessibility of resource and guidance support provided by school, faculty or university contributes to low quality of student's studies. They propose that the main responsibility of institutions of higher learning is to ensure that the services and facilities provided are always in an appropriate manner. This is to enable students to work and study in a conducive and comfortable environment.

Abidin (2011) asserts that research is an interactive process and requires the development of social as well as academic skills. The School of Graduate Study's function is commonly interpreted as referring to managing, operating or directing an organization in order to support students towards the completion of their post graduate studies. Some suggestions which Abidin puts forward regarding the supervisory framework for supporting and defining the students' graduate programme include:

- Producing a definite plan in writing, probably different for each department which describes the department's view on good supervisory practice

- Establishing regular meetings between student and supervisor, setting up

- Adequate methods of assessing coursework, thesis or dissertation supervision record keeping and project advancement and submitting a comprehensive annual progress report to the supervisor.

He further claims that Faculty and Graduate School Office is the major source of academic guidance for graduate students and they should go there and feel at ease discussing their problems and asking for advice. On the other hand, the students consult their academic advisor if they have academic problems.

Mutula (2009) cited in Wadesango and Machingambi (2011), postulate that post graduate research is a form of apprenticeship taken under the supervision of senior faculty members. The faculty member involved in the supervision of post graduate research must therefore have the right expertise to play the role of promoter/ supervisor. It has been found that misinformed or inadequately prepared supervisor whose research interests are different from those of the student are 
some of the factors that derail students from completing their studies. The relevant school of post graduate studies should therefore ensure that the student has been appointed a supervisor who has a similar interest and expertise in the student's research area and should match the personalities of supervisors and students (Sudmont and Hawkey, 2000). In the UK, the Quality Assurance Agency (QAA) stipulates that:

- Supervisors should possess recognised subject expertise.

- Supervisors should have the necessary skills and experience to monitor, support and direct research students' work.

- Research students should receive support and direction sufficient to enable them to succeed in their studies.

- The progress made by research students should be consistently monitored and regularly communicated to the students (Lubbe et al. 2005 in Wadesango and Machingambi, 2011).

In a study conducted by Wadesango and Machingambi (2011), it was established that some post graduate students have a lot of reservations with regard to supervisors' knowledge and expertise in their fields of study. While students admitted that expecting supervisors to have expertise in the precise topics of their research would be asking too much, they however, maintained that supervisors need to be well versed with the general methodologies required in their research. A related issue raised by $\mathrm{PhD}$ students in their study relate to the apparent lack of experience in research and/ or supervision by some supervisors. The twin challenges of limited knowledge and expertise as well as the lack of experience in research supervision by supervisors has grave implications on the quality of graduate research. It is axiomatic that a supervisor with limited knowledge and expertise in the field of study or in research supervision poses numerous problems for graduate research students. It is therefore important for supervisors to be trained so that they will be able to offer appropriate academic support to post graduate students. Deist (1990:67) in Lessing \& Schulze (2002) sees the task of the supervisor as ensuring that:

- the topic on which a candidate embarks does indeed present a problem;

- the candidate has a clear understanding of the field in which the problem occurs and of the problem itself;

- the candidate uses the correct methods to solve the problem and does an extended literature study of appropriate sources; and

- the problem is solved according to the requirements of the methods employed.

In support, Lessing \& Schulze (2002) citing Mouton (2001:17) see the role of the supervisor as to guide, advise, ensure scientific quality and provide emotional support. In addition to what has been given above, the following are some of the strategies that can be used by universities to support post graduate students academically:

\subsection{Academic Skills Workshops}

Academic Skills Workshops should be offered to postgraduate students on a range of topics. These workshops provide an opportunity for students to enhance the academic skills that will be required throughout their studies and for postgraduates to refresh their skills if returning to study after a long break from academia.

\subsection{Academic Writing Centre}

Universities should establish The Academic Writing Centre for postgraduate students and these centres should be manned by senior students and academic development consultants so as to providing a range of tips to assist the students in their academic work. It is important for post graduate students to acquire technical competence as well as be able to analyze data, manage their time and personal responsibilities, and build up a network of peers and expert colleagues. This service should be available on a one-to-one basis.

\subsection{Peer Tutoring Program}

It is imperative for universities to establish Peer Tutoring programmes which offer academic support for students through small group sessions or one-on-one tutoring. This is normally facilitated by trained peer tutors. This assistance has been found to help students to develop a deeper understanding of course concepts with the support of tutors who clarify difficult course material, review homework assignments and provide motivation as role models. 


\section{Conclusions}

The discussion shows the importance of postgraduate research studies in equipping graduates with analytical and problem-solving skills necessary to drive the knowledge economy. Postgraduate studies may be negatively affected by students' delayed or non-completion of theses and dissertations. This, invariably, results in low graduation rates and reduced number of postgraduates required to service the economy. Whilst academic support for students is often targeted on undergraduate students, postgraduate students require deliberately planned and implemented academic support programmes. This will go a long way in enhancing completion rates at postgraduate level. In this view, there are numerous strategies that academic development centres could utilise to ensure postgraduate students' support.

\section{Recommendations}

In view of issues raised in this discussion paper, the following recommendations are made;

a) Universities should invest in expanding postgraduate programmes to ensure that many students who qualify for postgraduate studies are enrolled for Masters and PhD degrees.

b) Incentives should be offered to students who enrol for postgraduate studies to encourage these and other students to undertake postgraduate studies. Some of the incentives may include fee remission, loans and bursaries.

c) Industry should link with higher education institutions closely to ensure that knowledge and skills required in industry are offered in universities. This will assist in the production of postgraduates with relevant knowledge and skills.

d) Academic development centres in universities should cater for post graduate students in academic development initiatives. Postgraduate students, like any other students, require academic support.

\section{References}

Abidin, N.Z. (2011). Attrition and completion issues in Post Graduate Studies for student development. International Review of social Sciences and Humanities, 1 (1): 15-29.

Armistead, C. (1999). Knowledge Management and Process Performance. Journal of Knowledge Management, 3 (2): 143-154)

Auriol, L. (2010). Careers of Doctorate Holders: Employment and Mobility Patterns. Paris: OECD Science

Badat, S. (2010). The Challenges of Transformation in Higher Education and Training Institutions in South Africa. New Delhi: India.

Bell, D. (1973). The Coming of Post-Industrial Society. New York: Basic Books.

Blankley, W.O., Booyens, I. (2010). Building a knowledge economy in South Africa. South African Journal of Science. 106 (11/12): 373 379

Brinkley, I. (2006). Defining the knowledge economy. Knowledge economy programme report. The work foundation.

Burger, S (2013) Strong university-industry links key to tapping knowledge-economy spin-offs. From www.engineeringnews.co.za/.../strong-university-industry-links-key-to-t... (Retrieved on 01 May 2014).

Castells, M. (2000). The Information Age. Economy, Society and Culture. Volume 1. The Rise of the Network Society. Oxford: Blackwell.

Connell, R. (1985). How to Supervise a PhD. Vestes, 2: $38-41$

Cowen, R. (1996) Performativity, Post-modernity and the University. Comparative Education, 32(2), 245-258.

Deem R., \& Brehony, K.J. (2000) Doctoral students' access to research cultures - are some more equal than others? Studies in Higher Education, 25(2), 149-165.

Deist, F.E (1990). The role of the promoter. Theologia Evangelica 23(3):66 \pm 68 .

Dietz, A.J., Jansen, J.D. \& Wadee, A.A. (2006). Effective PhD Supervision and Mentorship. A Workbook Based on the Experiences from South Africa and the Netherlands. Pretoria: UNISA.

Department for Business, Innovation and Skills (2009). Higher Ambitions: the future of universities in s knowledge economy. London: UK Government

Department of Education, Training and Youth Affairs (1998). Report No. 33. Research Training for the 21st Century. Canberra: DETYA

Department of Education, Education Statistics at a Glance (2003-2005)

Du Pre, M. (2013). Strong university-industry links key to tapping knowledge-economy spin-offs. From www.engineeringnews.co.zal.../strong-university-industry-links-key-to-t... (Retrieved on 01 May 2014).

Green B., \& Lee. A. (1999) Educational research, disciplinarity and postgraduate pedagogy: on the subject of supervision. In A. Holbrook \& \& S. Johnston (Eds.), Supervision of Postgraduate Research in Education, Review of Australian Research in Education. Coldstream: Australian Association for Research in Education.

Green, K. E. (1997), Psychosocial factors affecting dissertation completion. New Direction for Higher Education 99: 57 - 64

Griesel, H., Parker, B. (2009). Graduate Attributes: A baseline study on South African graduates from the perspectives of employers. Pretoria: Higher Education South Africa \& South African Qualifications Authority 
Harvey, D. (1989). The Condition of Postmodernity. Oxford: Basil Blackwell.

Hazelkorn, E. (Ed) (2005). University Research Management. Developing Research in New Institutions. Paris: OECD

Ho, J. C. W., Wong. L. C. J. and Wong P.T.P (2010). What helps and what hinders theses completion: A critical incident study. International Journal of Existential Psychology and Psychotherapy, 3(2), 117-131

Hollingsworth, M.A., Fassinger, R.E, (2002). The role of faculty mentors in the research training of counseling psychology doctoral students. Journal of Counselling Psychology. 49:324-330.

Houghton, J., Sheehan, P.A. (2000). A primer on the knowledge economy. CSES Working Paper No. 8 Melbourne: Centre for Strategic Economic Studies, Victoria University of Technology

Johnston, R. (1998). The Changing Nature and Forms of Knowledge: A Review. Canberra: DETYA.

Kamler, B. \& Thompson, P. (2008). The Failure of Dissertation Advice Book: Toward Alternative Pedagogies for Doctoral Writing. Educational Researcher.3 (7):507-513.

Kearney, M.L (2008). The Role of Post Graduate Education in Research Systems. Paper presented for the UNESCO/DCU Workshop on Trends in postgraduate Education. 5 - 7 March 2008. Dublin City University, Ireland

Leadbeater, C. (1999). Living on thin air, London: Viking, Penguin

Lessing, A.C \& Schulze, S. (2002). Postgraduate supervision and academic support: students' perceptions. South African Journal of Higher education, 16 (2): 139-149

Johnston, S. (1999). Research Supervision - Setting the Scene. In A. Holbrook \& S. Johnston (Eds.), Supervision of Postgraduate Research in Education (pp. 17-31). Victoria: AARE

Kemp, D. A. (1999). Knowledge and Innovation: A Policy Statement on Research and Research Training. Canberra: AGPS.

Kickert, W. (1991) Steering at a distance: A new paradigm of public governance in Dutch higher education.

Knight, J. \& Lingard, B. (1997) Ministerialisation and Politicisation: Changing Structures and Practices of Educational Policy Production. In B. Lingard \& P. Porter (Eds.), A National Approach to Schooling in Australia? Essays on the Development of National Policies in Schools Education. Canberra: Australian College of Education.

Laske, S. and Zuber-Skerritt, O. (1996). Frameworks for Postgraduate Research and Supervision. Lismore: Southern Cross University Press

Lubbe, S., Worrel L and Klopper, R (2005). Challenges in Postgraduate Research. Durban: Dolphin Pub.

Lyotard, J. F. (1985). The Postmodern Condition: A Report on Knowledge. Minneapolis: University of Minnesota Press.

Mouton, J. (2001). How to succeed in your master's \& doctoral studies. Pretoria: Van Schaik.

Mouton, J. (2007). Postgraduate studies in South Africa: Myths, Misconceptions and challenges. South African Journal of Higher Education.21 (8):1078-1090.

Murray, R. (2002). How to write a thesis. Buckingham: Open University Press

Mutula, S.M (2009). Building Trust in Supervisor-Supervisee Relationship: Case Study of East and Southern Africa. Paper Presented at the Progress in Library and Information Science in Southern Africa (PROLISSA) Conference at the University of South Africa (UNISA), March 4-6, 2009

Phillip, E.M., Pugh, D.S. (2005). How to get a PhD: A handbook for students and supervisors, Maidenhead: Open University Press

Powell, W.W., Snellman, K. (2004). Knowledge Economy. Annual Review of Sociology 30: 199 - 220

Rowley, J. (2000). Is Higher Education Ready for Knowledge Management? The International Journal of Education Management. 14 (70, pp. 325-333

Singh, P and Knight, J (2005). HE knowledge economy and higher degree research training. UK: Queensland University of Technology

Sudmant, W and Hawkey, C. (2000). Flow of Post-Secondary Graduates into the Knowledge Economy: Evidence from the National Graduate Survey. UK: University of British Columbia

Tzanakou, C. (2012). Beyond the PhD: the significance of boundaries in the early careers of highly qualified Greek scientists and engineers. PhD Thesis, University of Warwick.

Qhena, G (2013). Strong university-industry links key to tapping knowledge-economy spin-offs. From www.engineeringnews.co.za/.../strong-university-industry-links-key-to-t... (Retrieved on 01 May 2014).

Wadesango, N and Machingambi, S (2011). Post Graduate Students' Experiences with Research Supervisors. Journal of Sociology and Social Anthropology, 2 (1): 31-37

Zhao, F (2001). Postgraduate Research Supervision: A Process of Knowledge Management. Bundoora West: RMIT University 